Journal of the Electrochemical Society, 1998, Volume 145, Issue 7, Pages 2258-2264.

ISSN: (Print 0013-4651) (Online 1945-7111)

DOI: $10.1149 / 1.1838630$

http://www.electrochem.org/

http://scitation.aip.org/JES

http://www.ecsdl.org/getpdf/servlet/GetPDFServlet?filetype=pdf\&id=JESOAN000145000007002258000001\&idtyp e=cvips\&prog $=$ normal

(C) The Electrochemical Society, Inc.1998. All rights reserved. Except as provided under U.S. copyright law, this work may not be reproduced, resold, distributed, or modified without the express permission of The Electrochemical Society (ECS). The archival version of this work was published in Journal of the Electrochemical Society, 1998, Volume 145, Issue 7, Pages 2258-2264.

\title{
Corrosion Protection of Untreated AA-2024-T3 in Chloride Solution by a Chromate Conversion Coating Monitored with Raman Spectroscopy
}

\author{
Jun Zhao, and Richard L. McCreery \\ Department of Chemistry, The Ohio State University, Columbus, Ohio
}

\section{Gerald Frankel}

Department of Materials Science and Engineering, The Ohio State University, Columbus, Ohio

\begin{abstract}
The behavior of chromate conversion coatings (CCCs) on the aluminum aircraft alloy AA 2024-T3 was examined by several types of experiments, using Raman spectroscopy as a primary technique. First, Raman spectra of the CCC film made from a commercial process revealed a Raman feature characteristic of $\mathrm{Cr}(\mathrm{VI})$ which was distinct from Raman bands of pure $\mathrm{CrO}_{4}^{-2}$ or $\mathrm{Cr}_{2} \mathrm{O}_{7}^{-2}$. Second, Raman spectroscopy was used to monitor migration of chromate species from a CCC film to an initially untreated alloy sample. The release of chromate from a CCC was demonstrated, as was redeposition of a chromate film on the fresh alloy surface. Formation of a Raman-observable $\mathrm{Cr}(\mathrm{VI})$-containing deposit was more rapid in or near pits in the untreated alloy sample, and the deposit was spectroscopically very similar to the original CCC film. The initially untreated alloy became much less active toward corrosion after migration of chromate from the nearby $\mathrm{CCC}$ film, with the polarization resistance increasing by at least two orders of magnitude and the pitting potential increasing by $60 \mathrm{mV}$. The results clarify the mechanism of self-healing exhibited by CCC films, in which chromate species released from the CCC migrate to an actively corroding region and stop aluminum dissolution. The migrating chromate is selectively deposited at active corrosion sites, either by forming an insoluble $\mathrm{Al} /$ chromate is selectively deposited at active corrosion sites, either by forming an insoluble $\mathrm{Al} /$ chromate precipitate or by adsorption by previously formed corrosion
\end{abstract}

\section{Introduction}

A recent view of aircraft coating technology concluded that understanding the mechanisms of aluminum corrosion and chromate inhibition is a top priority and a prerequisite for developing replacements for coatings based an toxic $\mathrm{Cr}(\mathrm{VI}) .{ }^{1}$ It has been established that chromate ions increase the pitting potential of aluminum alloys in the chloride media and reduce the rates of pit nucleation and growth. ${ }^{2-4}$ Chromate conversion coatings (CCC) formed by immersion of aluminum alloys in an acidic solution of chromate and fluoride have been used for years to inhibit aluminum corrosion. Such films have been shown to contain both $\mathrm{Cr}$ (III) and $\mathrm{Cr}(\mathrm{VI})$, with relative concentrations depending on the pretreatment procedure. ${ }^{5-7}$ It is generally believed that $\mathrm{CCC}$ formation involves destabilization of the passive oxide film by fluoride, followed by reduction of chromate by the exposed aluminum (Eq. 1) $)^{8-9}$ 


$$
2 \mathrm{Al}+\mathrm{Cr}_{2} \mathrm{O}_{7}^{-2}+8 \mathrm{H}^{+} \rightleftarrows 2 \mathrm{Cr}(\mathrm{OH})_{3}+\mathrm{H}_{2} \mathrm{O}+2 \mathrm{Al}^{+3}
$$

The precise hydration state and speciation of $\mathrm{Cr}(\mathrm{III})$ and $\mathrm{Al}(\mathrm{III})$ in Eq. 1 vary with conditions, and the components in Eq. 1 are only one of several possibilities.

The mechanism of corrosion inhibition by CCC films has been proposed to involve blocking of active pores and defects by the $\mathrm{Cr}$ (III) film, ${ }^{10}$ an increase in electrical resistance in the (CCC), ${ }^{11}$ or dynamic repair of newly created breaks or defects in the protective film. ${ }^{9,12}$ The latter mechanism is quite important to the use of CCCs, since it provides a means for the "selfhealing" observed for chromate films. The possibility of migration of a $\mathrm{Cr}(\mathrm{VI})$ species to an active corrosion site, and subsequent blocking of corrosion, is a likely reason why CCC films are so effective in the field. This phenomenon is evidenced, for example, by the minimal corrosion that occurs after salt-spray testing even when the sample has a scribe mark through the coating to the metal alloy substrate. Chromate-replacement coating schemes need to mimic this "selfhealing" phenomenon in some way. Chromate migration and reprotection is a primary issue in the current report.

Raman spectroscopy has been used extensively for studying electrochemical interfaces ${ }^{13-}$ 19 and other surfaces, but less commonly for studying corrosion. Raman provides information about bonding and molecular structure which complements information about elemental composition and oxidation state available from X-ray photoelectron spectroscopy and X-ray fluorescence techniques. Vibrational spectra can be particularly useful for identifying specific metal oxide species and for deducing oxide film structure. Raman spectroscopy has been used in the past to examine corrosion of iron, ${ }^{20-23}$ chromium, ${ }^{20,21}$ and aluminum. ${ }^{22-24}$ In some cases, Raman spectroscopy permitted the identification of particular species (e.g., $\mathrm{Cr}_{2} \mathrm{O}_{3}$ vs. $\mathrm{Cr}(\mathrm{OH})_{3}$, $\mathrm{Fe}(\mathrm{OH})_{3}$ vs. FeOOH), and Raman spectra can often be acquired in situ. ${ }^{19}$ When examining surfaces which exhibit surface-enhanced Raman spectroscopy (SERS) such as gold, silver, and copper, Raman spectroscopy can provide detection limits much lower than one monolayer of adsorbate. Even without surface enhancement, Raman spectra may be obtained from submonolayer adsorbates on metal and carbon surfaces. ${ }^{25,21}$

Raman spectroscopy with a $514.5 \mathrm{~nm}$ laser is very sensitive to $\mathrm{CrO}_{4}^{-2}$ and $\mathrm{Cr}_{2} \mathrm{O}_{7}^{-2}$ both in solution and in thin films, and is quite applicable for studying chromate coatings. In the current work, Raman spectroscopy was used to monitor $\mathrm{Cr}(\mathrm{VI})$ species in CCCs and in solutions in contact with aluminum alloys and CCCs. In addition, the migration of $\mathrm{CrO}_{4}^{-2}$ from a $\mathrm{CCC}$ to bare aluminum alloy was investigated, as were the effects of $\mathrm{CrO}_{4}^{-2}$ on protection of an initially unprotected surface.

\section{Experimental}

Sample preparation.-CCCs were prepared from Alodine 1200S (Parker Amchem), which was used as received, and all other chemicals were reagent grade. All experiments were conducted in "Nanopure" (Barnstead) water (resistivity $>18 \mathrm{M} \Omega \mathrm{cm}$ ). Aluminum alloy AA 2024T3 (0.7 mm thick) was cut into $1 \mathrm{~cm}$ squares or $19 \mathrm{~mm}$ disks, then mounted in epoxy resin from Buehler. In many cases, copper wires were attached to the back of the alloy coupon with silver epoxy before mounting. The exposed face of the coupon was polished with a Buehler Economet 3 variable speed polisher with a series of abrasive papers $(240,400,600,800,1200$ grit) in distilled water. No other solvents were used during sample preparation, in order to avoid possible organic contamination. 
A CCC film was formed on polished alloys by immersion in a solution of $1.51 \mathrm{~g}$ Alodine powder in $200 \mathrm{~mL}$ Nanopure water, adjusted to $\mathrm{pH} 1.69$ with $\mathrm{HNO}_{3}$. After $60 \mathrm{~s}$ of immersion at room temperature, the samples were immediately rinsed with water, then soaked for $90 \mathrm{~s}$ each in three portions of $80 \mathrm{~mL}$ of water. The CCC samples were then dried and aged in air for 10 days, unless stated otherwise.

Raman spectroscopy. - A custom Raman spectrometer described previously ${ }^{27}$ was used for both spectroscopy and microprobe analysis. A Kaiser "Holospec" spectrograph $(f / 1.8)$ and Photometrics back thinned charge coupled device (CCD) (TK512 CB/AR) were preceded by f/1.4 collection optics operating in $180^{\circ}$ backscattering geometry. A $514.5 \mathrm{~nm}$ laser beam with typically $50 \mathrm{~mW}$ at the sample was combined with the collection beam using a small planar mirror. A swing mirror and a video CCD camera provided a video image of the sample, with approximately $15 \mu \mathrm{m}$ spatial resolution, so that the laser spot could be located with respect to visual features on the sample. Motion of the swing mirror out of the collection beam axis allowed acquisition of a Raman spectrum from the same spot on the sample surface. The system covered the Raman shift range of $300-1700 \mathrm{~cm}^{-1}$ in one exposure. Integration times were in the range of 0.5 to $60 \mathrm{~s}$. Unlike gold, silver, and copper surfaces, aluminum alloys are not known to support surface-enhanced Raman spectroscopy, and no special roughening procedures were employed.

Electrochemistry.-Polarization resistance in $0.1 \mathrm{M} \mathrm{NaCl}$ was measured by linear polarization with a PGP201 potentiostat (Radiometer), a saturated calomel reference electrode, and a Pt foil $\left(2 \mathrm{~cm}^{2}\right)$ electrode. A $\pm 20 \mathrm{mV}$ or $\pm 30 \mathrm{mV}$ potential cycle was applied to the sample at $50 \mathrm{mV} / \mathrm{min}$ starting at the open-circuit potential. $R_{\mathrm{p}}$ was determined as the inverse of the slope of the current density vs. potential curve. In the potentiodynamic polarization experiments, a potential scan was initiated at the open-circuit potential $\left(E_{\text {corr }}\right)$ in the positive direction at 100 $\mathrm{mV} / \mathrm{min}$. The scan was stopped when the current reached $100 \mu \mathrm{A} / \mathrm{cm}^{2}$ then reversed after a pause of $10 \mathrm{~s}$. The breakdown potential, $E_{\mathrm{brk}}$, was defined as the potential when the current reached 100 $\mu \mathrm{A} / \mathrm{cm}^{2}$, similar to the definition of pitting potential by Kendig et al. ${ }^{28}$

The X-ray photoelectron spectrometer (XPS) was a Vacuum Generators Escalab with diffusion pumping and a base pressure of $\sim 5 \times 10^{-10}$ Torr.

\section{Results}

Raman spectroscopy is used here to monitor chromate concentration in solution, and to indicate the presence of a CCC film. Raman spectra of several chromate species are shown in Fig. 1. Chromate and dichromate are easily observed in solution and can be distinguished from each other by the peak position. The Alodine solution is primarily dichromate as it should be, given its low $\mathrm{pH}$. The $1046 \mathrm{~cm}^{1}$ bond for $\mathrm{NO}_{3}$ originates with the $\mathrm{HNO}_{3}$ used to adjust the Alodine bath $\mathrm{pH}$. The CCC shows a Raman band close to that of $\mathrm{CrO}_{4}^{-2}$, but significantly broadened. The chromate species in the $\mathrm{CCC}$ could be a combination of $\mathrm{CrO}_{4}{ }^{-2}$, and $\mathrm{Cr}, \mathrm{O}_{7}{ }^{-2}$, or possibly a polymeric oxide. Raman bands for $\mathrm{Cr}_{2} \mathrm{O}_{3}$ and $\mathrm{Cr}(\mathrm{OH})_{3}$ exist at about $560 \mathrm{~cm}^{1}$, but these were not observed in the CCC. Since the Cr(III) species are weaker Raman scatterers than $\mathrm{Cr}(\mathrm{VI})$ under the conditions employed, the technique is not very sensitive to the former. As a result, the absence of $\mathrm{Cr}$ (III) Raman features in the CCC spectrum does not necessarily indicate they are not present. Although the structural details underlying the broad band for the CCC are not clear, we can say that it is due mainly to $\mathrm{Cr}(\mathrm{VI})$ species, and it is a useful marker for the 
presence of the CCC.

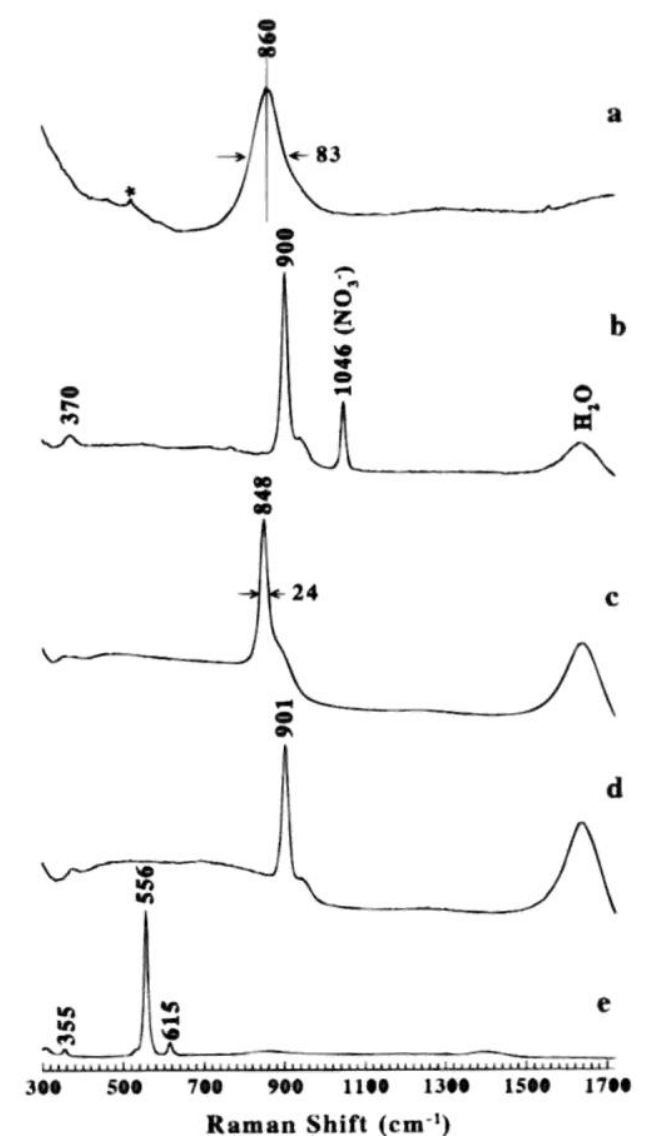

Fig. 1. Raman spectra obtained with a $514.5 \mathrm{~nm}$ laser, $20 \mathrm{~mW}$ at sample, with integration times indicated in parentheses: (a) CCC film on AA2024-T3 (10 s); (b) Alodine solution (10 s); (c) $8.6 \times 10^{-3} \mathrm{M} \mathrm{K}_{2} \mathrm{CrO}_{4}$ (1 s); (d) 4.2 $\times 10^{-3} \mathrm{M} \mathrm{K}_{2} \mathrm{Cr}_{2} \mathrm{O}_{7}(1 \mathrm{~s})$; (e) $\mathrm{Cr}_{2} \mathrm{O}_{3} / \mathrm{H}_{2} \mathrm{O}$ paste $(1 \mathrm{~s})$. Intensity scale is arbitrary and varies for different spectra.

The principal issue of this investigation is the possibility of migration of chromate from a CCC to a region of exposed alloy, and subsequent protection. To overcome the inherent difficulties associated with the reproducibility of a scratch, the cell of Fig. 2 was utilized. This cell can be considered an "artificial scratch" as it isolates an abraded but otherwise untreated alloy sample from a CCC-treated alloy sample, with a $1.8 \mathrm{~mm}$ thick layer of solution between the two. Any chromium species found on the initially untreated alloy surface must have migrated across the solution gap from the CCC. In addition, if protection of the untreated surface is observed after the "artificial scratch" cell is disassembled, the protection must have resulted from the nearby presence of the CCC film. "Artificial scratch" experiments were conducted for various lengths of time (1-96 h) and for various conditions: with and without an O-ring to restrict air exposure and with and without electrical contact between the two alloy samples. In all cases, the cells were placed in a closed vessel containing water to maintain humidity. Control experiments without the CCC present (both samples untreated) were also conducted. 


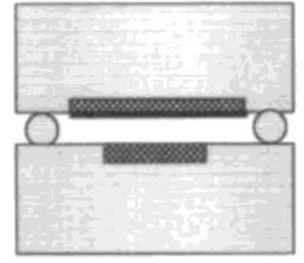

a1

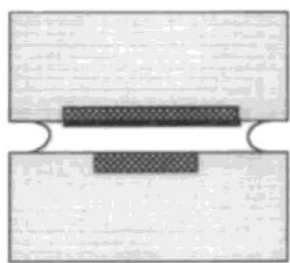

b1

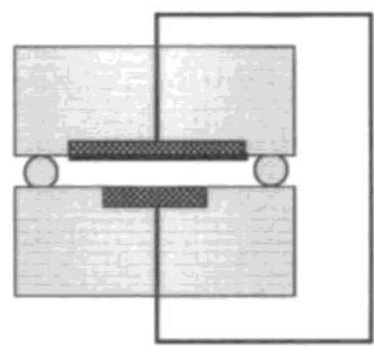

a2

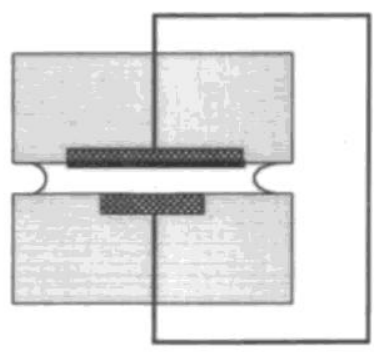

b2

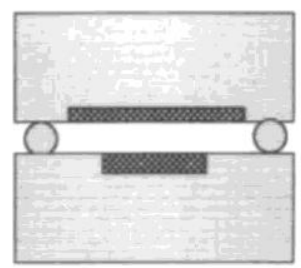

a3

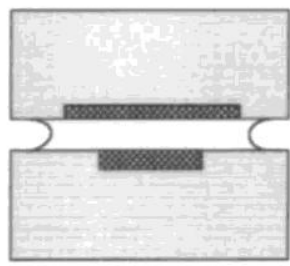

b3

Fig. 2. Schematic drawing of artificial scratch cells. Black line in al, a2, bl, and b2 indicates CCC film positioned 1.8 $\mathrm{mm}$ from a polished, untreated alloy sample. Cells a3 and b3 were control cells lacking the CCC film, a 1 -a3 were sealed with an O-ring which reduced air exposure, while bl-b3 were exposed to air at the solution edge. Cells a2 and b2 had a copper wire connecting the two alloy samples.

Micrographs of the initial alloy surface and after $96 \mathrm{~h}$ in a $0.1 \mathrm{M} \mathrm{NaCl}$ artificial scratch cell are shown in Fig. 3a and b. Polishing scratches were still visible on the initially unprotected alloy after $96 \mathrm{~h}$, indicating a lack of significant general corrosion. Only a few small pits formed on the initially unprotected surface. The control sample (a3-72) shown in Fig. 3 exhibited severe pitting and general corrosion, and a significant amount of white corrosion product was evident. Unaided visual observation revealed obvious corrosion of sample a3, while al was shiny with minor evidence of corrosion product, and a2 was both shiny and smooth. Although the samples without (al, bl) and with (a2, b2) electrical contact both showed greatly reduced corrosion compared to the controls (a3, b3), an electrical connection between the two alloy samples appeared to reduce pitting somewhat in the initially untreated alloy samples. The micrographs indicate that the initially untreated alloy was protected by the presence of a CCC film which was $1.8 \mathrm{~mm}$ away in the same solution. Very similar results were obtained if the solution had contact with air.

The epoxy-mounted samples were not subjected to XPS analysis, in order to avoid placing epoxy in the ultrahigh vacuum (UHV) chamber. A sample for XPS analysis was prepared by placing a polished but unmounted alloy coupon on top of a CCC-treated sample in $0.1 \mathrm{M} \mathrm{NaCl}$ for $20 \mathrm{~h}$. XPS spectra of this sample are shown in Fig. 4. XPS analysis of this sample revealed chromium and fluorine in addition to the expected aluminum and oxygen (Fig. 4). $\mathrm{Ar}^{+}$sputtering of the surface for a short time removed the $\mathrm{Cr}$ and $\mathrm{F}$, revealed copper, and reduced the oxygen/Al ratio. These spectra demonstrate that chromium in some form has 
migrated from the CCC film and deposited on the initially clean alloy, along with some fluorine. High resolution XPS indicated that the chromium was in the +6 oxidation states, (but there is uncertainty about whether the oxidation states are perturbed by the XPS measurement ${ }^{29,30}$ ). High resolution XPS also indicated that the surface aluminum was in the +3 oxidation state, and that A1(0) was exposed upon sputtering.

The molecular identity of the chromate species is revealed in part by the Raman spectra of the initially unprotected alloy surface. The magnified video image of this surface showed two types of pits, which appeared either light or dark in the image. By visual examination, the light pits contain more corrosion product, and the dark pits much less. Raman spectra on or near these two pit types are shown in Fig. 5, along with that of the smooth surface away from any pit. The "light" pits have a spectrum similar to that of the CCC film, with a broad band at $852 \mathrm{~cm}^{-1}$. The "dark" pits have a similar but much weaker band, and the $852 \mathrm{~cm}^{1}$ band was not observed on an unpitted region. These results indicate that a material chemically similar to the Alodine CCC is forming in or near pits on the initially unprotected alloy, during solution exposure to a CCC treated alloy. The absence of Raman features on the smooth surface does not necessarily indicate that a chromium-containing film is not present, since the amount of chromate concentration may be below the Raman detection limit, or the $\mathrm{Cr}(\mathrm{VI})$ may have been reduced to $\mathrm{Cr}(\mathrm{III})$. Since the XPS analysis area is much larger than the pits, the Cr speciation indicated by XPS may represent an average of a large area. In addition, Raman is less sensitive to $\mathrm{Cr}$ (III) oxides than to chromate, so $\mathrm{Cr}_{2} \mathrm{O}_{3}$ or its hydrates may be present in pits or on smooth regions. The difference between light and dark pits is apparently due to a chromate-containing corrosion product which forms in the light pits and scatters the light forming the video image. For reasons not yet apparent, the dark pits have less of this product, or the product is not stable over time. It is important to emphasize that both light and dark pits are small and apparently inactive, and that the sample does not exhibit widespread corrosion after $96 \mathrm{~h}$ in $0.1 \mathrm{M} \mathrm{NaCl}$. The principal conclusion from the Raman results is that chromate species migrate from a CCC film to an initially unprotected surface, and that a product chemically similar to the original CCC film forms in or around the pits.

Electrochemical assessments of protection included observations of open-circuit potential $\left(E_{\text {corr }}\right)$, breakdown potential $\left(E_{\mathrm{hrk}}\right)$, and polarization resistance $\left(R_{\mathrm{p}}\right)$. A freshly polished, unprotected surface had an $E_{\text {corr }}$ in aerated $0.1 \mathrm{M} \mathrm{NaCl}$ of $-555 \mathrm{mV}$ vs. SCE, and $E_{\mathrm{btk}}-480 \mathrm{mV}$. The $R_{\mathrm{p}}$ determined from linear polarization measurements such as those in Fig. 6 ranged from 8 $\times 10^{3}$ to $40 \times 10^{3} \Omega \mathrm{cm}^{2} . E_{\text {corr }}, E_{\text {brk }}$, and $R_{\mathrm{p}}$ for a CCC film varied with aging time and immersion time, ${ }^{31}$ and a range of values was obtained here. $E_{\text {corr }}$ for a CCC-treated sample increased from -690 to $-550 \mathrm{mV}$ vs. SCE, and $R_{\mathrm{p}}$ increased from $1.0 \times 10^{6} \Omega \mathrm{cm}^{2}$ to $7 \times 10^{6} \Omega \mathrm{cm}^{2}$ for immersion in $0.1 \mathrm{M} \mathrm{NaCl}$ from $15 \mathrm{~min}$ to $44 \mathrm{~h}$. $E_{\text {brk }}$ was $-440 \mathrm{mV}$ but also increased with time. Upon disassembly of the artificial scratch cell, the initially untreated samples were rinsed with water and immersed in air-exposed $0.1 \mathrm{M} \mathrm{NaCl}$ containing no chromate. Migration of chromate from a CCC film to an initially unprotected alloy (as in configuration a1) caused a dramatic increase in $R_{p}$, to values ranging from $0.8 \times 10^{6}$ to $3 \times 10^{6} \Omega \mathrm{cm}^{2}$ or approximately a factor of 100 higher than untreated alloy. $E_{\text {corr }}$ decreased to $-650 \pm 20 \mathrm{mV}$, and $E_{\text {brk }}$ increased to approximately $-420 \pm 30 \mathrm{mV}$. Comparison of the alloy protected by migration to the control (cell a3 or b3) revealed that the average difference between $E_{\text {corr }}$ and $E_{\text {brk }}$ increased from 75 to $230 \mathrm{mV}$. This increase is consistent with the larger $R_{\mathrm{p}}$ following migration. 


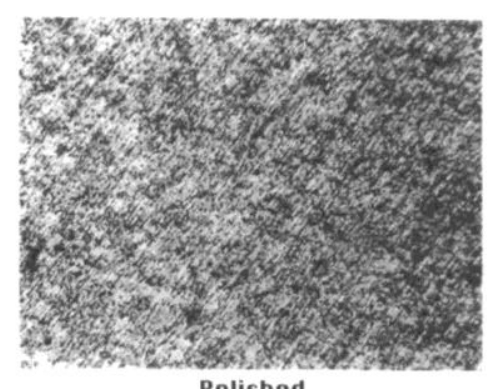

Polished

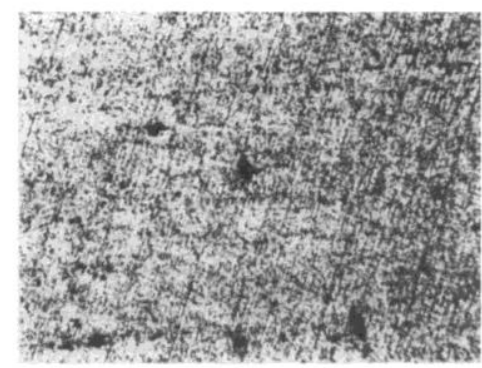

a $1-96$

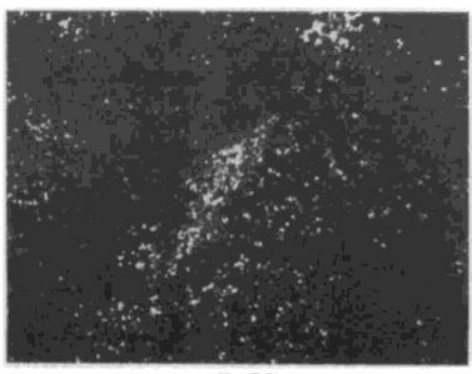

a3-72

Fig. 3. Photomicrographs of AA-2024 T3 alloy samples. All three were polished identically, and the upper micrograph shows an untreated sample, a 1-96 was an initially untreated sample after $96 \mathrm{~h}$ in $0.1 \mathrm{M} \mathrm{NaCl}$ in cell al from Fig. 2. a3-72 was an initially untreated sample after $72 \mathrm{~h}$ in $0.1 \mathrm{M} \mathrm{NaCl}$ in configuration a3, without CCC present. 


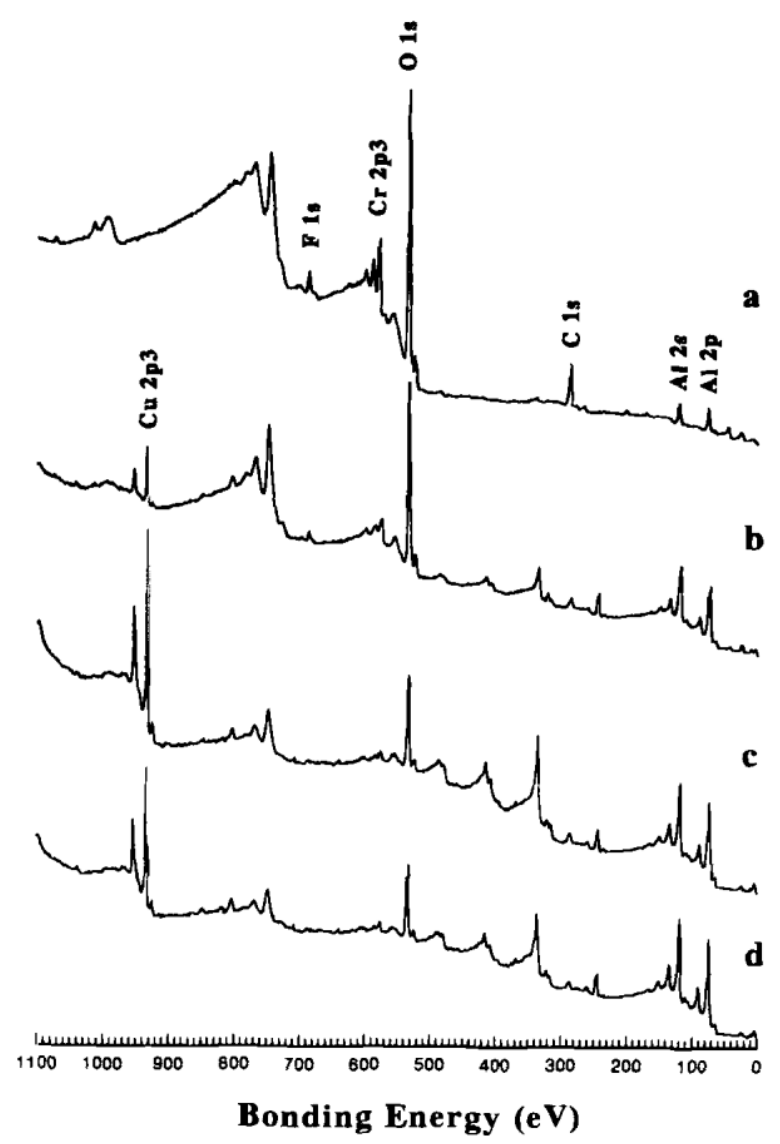

Fig. 4. XPS spectra of an initially untreated AA 2024-T3 sample following $20 \mathrm{~h}$ in an air-exposed $0.1 \mathrm{M} \mathrm{NaCl}$ solution. The sample was resting on a CCC film in order to allow migration of chromate species. Spectrum a is the initial spectrum, and b, c, d are after 3, 9, and 18 min of $\mathrm{Ar}^{+}$sputtering in UHV.

Figure 7 shows $R_{\mathrm{p}}$ for the initially untreated sample as a function of exposure time in the "artificial scratch" cell. Each point represents a separate experiment and sample. $R_{\mathrm{p}}$ increases from $\sim 10^{4}$ to $\sim 10^{6} \Omega \mathrm{cm}^{2}$ over about a $12 \mathrm{~h}$ period. Neither electrical connection of the two alloy samples (as in a2 and b2) nor exposure to air (as in b1 and b2) had an observable effect on $R_{\mathrm{p}}$.

The XPS and Raman results clearly demonstrate that chromium species migrate from the CCC film to the initially unprotected alloy, and the visual and electrochemical results indicate that the migrated chromium species provided corrosion protection. If the migrating species is in fact chromate (or dichromate), then it should be possible to observe chromate release from a $\mathrm{CCC}$ film into $0.1 \mathrm{M} \mathrm{NaCl}$, and to demonstrate protection of the alloy by the resulting dilute chromate species. 


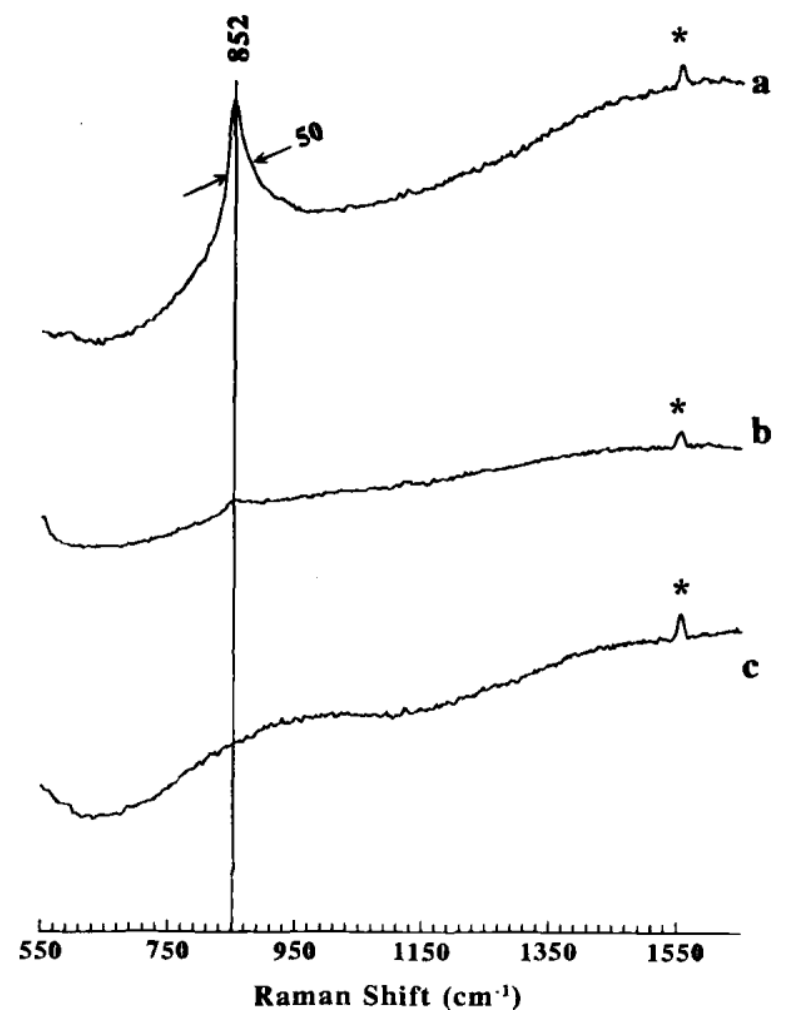

Fig. 5. Raman spectra of an initially untreated alloy sample after $48 \mathrm{~h}$ of exposure to $0.1 \mathrm{M} \mathrm{NaCl}$ in cell al. $514.5 \mathrm{~nm}$ laser, $20 \mathrm{~mW}$ at sample, averages of $201 \mathrm{~s}$ integrations, (a) laser focused on a light pit; (b) focused on a dark pit; (c) focused away from any visible pits. Asterisk indicates Raman scattering from atmospheric oxygen.

Chromate release was measured with Raman spectroscopy, by directing the laser beam through a drop of solution on a CCC film. A hole in the alloy sample permitted the beam to pass through the $1.0 \mathrm{~mL}$ drop of $0.1 \mathrm{M} \mathrm{NaCl}$, normal to the CCC surface, without sampling the CCC itself, and the sample was held in a humid atmosphere to prevent evaporation of the drop. A small chromate Raman band at $848 \mathrm{~cm}^{-1}$ developed with time. The $848 \mathrm{~cm}^{1}$ Raman intensity was calibrated with known solutions of $\mathrm{K}_{2} \mathrm{CrO}_{4}$ in $0.1 \mathrm{M} \mathrm{NaCl}$, so that the $\mathrm{CrO}_{4}^{-2}$ concentration released from the $\mathrm{CCC}$ film could be determined. The error bars are large due to the weak signal, but the results are shown in Fig. 8 . For a $1.0 \mathrm{~mL}$ drop covering $2.8 \mathrm{~cm}^{2}$ of CCC film, the $\mathrm{CrO}_{4}^{-2}$ concentration increased slowly over a $72 \mathrm{~h}$ period, and appeared to approach an equilibrium value. A CCC film that had been dried in air only $20 \mathrm{~min}$ after formation (upper curve) exhibited a release rate of (in terms of grams of released $\mathrm{CrO}_{4}^{-2}$ ) of $2 \times 10^{-7} \mathrm{~g} / \mathrm{cm}^{2} \mathrm{~h}$. Aging the CCC for 10 days (as was the case for most of the samples studied) reduced the release rate to $0.7 \times 10^{-7} \mathrm{~g} / \mathrm{cm}^{2}$ $\mathrm{h}$. The CCC film color did not change significantly during this experiment, but if the CCC sample was placed in a large volume of $0.1 \mathrm{M} \mathrm{NaCl}(80 \mathrm{~mL})$, the yellow color disappeared after $48 \mathrm{~h}$. The chromate concentration appeared to reach a saturation level in the small solution volume of the drop, perhaps due to an equilibrium with the CCC. For the large volume, equilibrium was not attained and most of the chromate in the CCC apparently dissolved. As noted earlier based on XPS results, fluoride ion is also released by the CCC. Furthermore, chromate was released whether or not chloride was present, or whether the solution was exposed to air. 

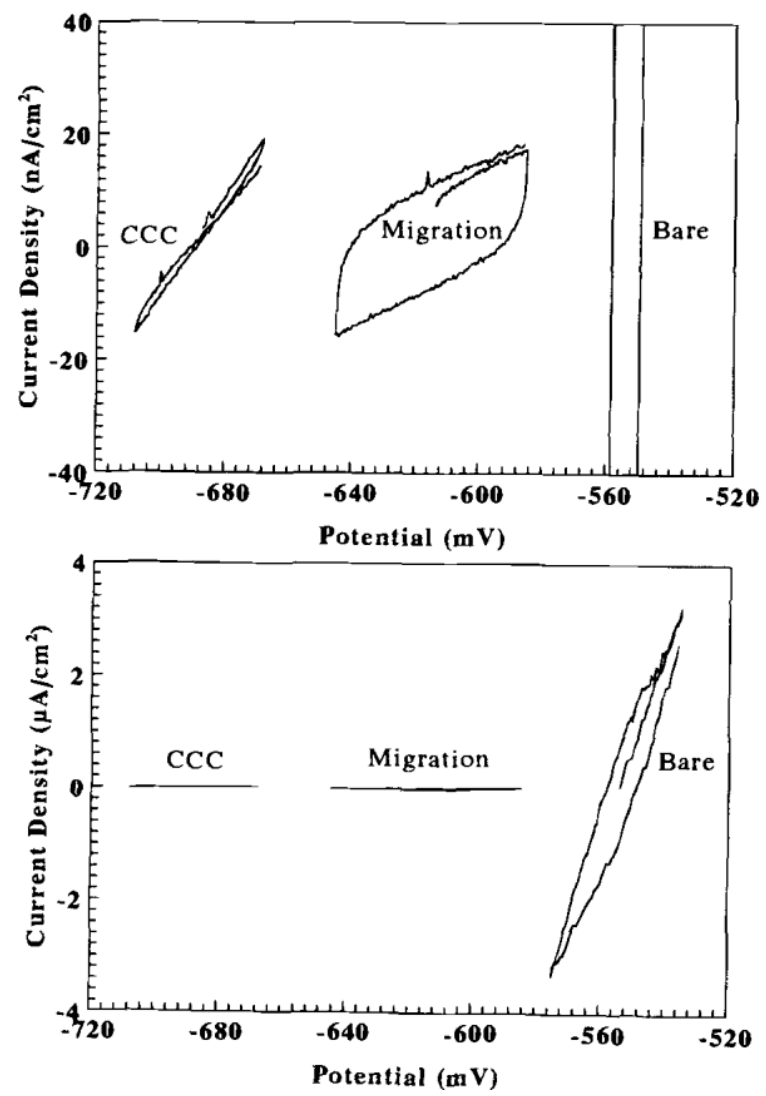

Fig. 6. Linear polarization voltammogram obtained in $0.1 \mathrm{M} \mathrm{NaCl}$ at $50 \mathrm{mV} / \mathrm{min}$. Upper and lower plots differ only in current scale. "Bare" is an initially untreated alloy sample after $48 \mathrm{~h}$ in cell b3, which does not contain a CCC. "Migration" is the same, except after exposure in cell b2, opposite a CCC. "CCC" is an alloy sample with a standard CCC.

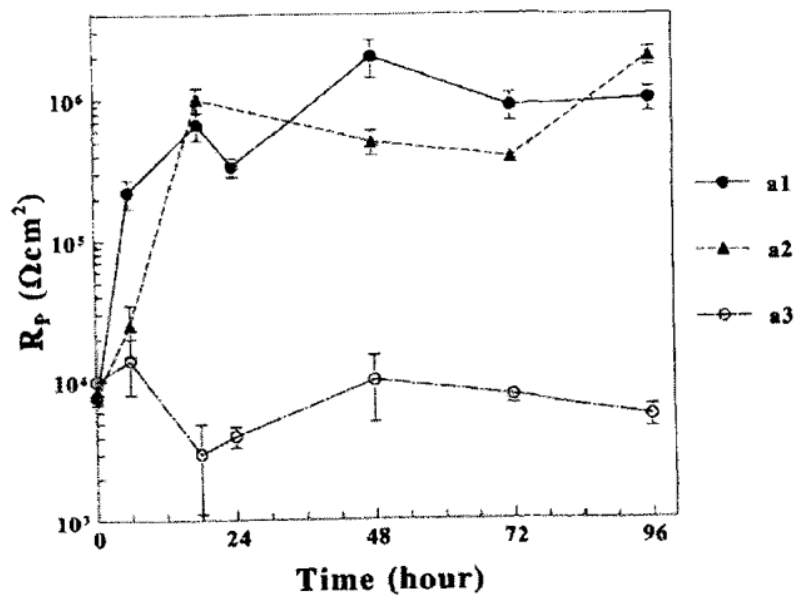

Fig. 7. Polarization resistance for initially untreated alloy samples exposed in cells a1, a2 and a3 for varying lengths of time. Each datum point is from a separate cell, which was disassembled, rinsed, and placed in $0.1 \mathrm{M} \mathrm{NaCl}$ for the $R_{\mathrm{p}}$ measurement. 


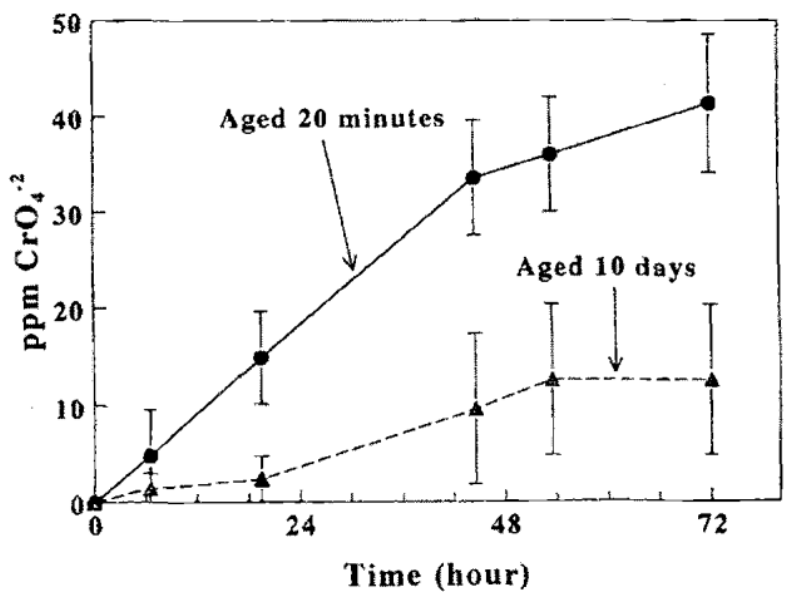

Fig. 8. Chromate concentration released from $2.8 \mathrm{~cm}^{2}$ of a $\mathrm{CCC}$ film into a $1.0 \mathrm{~mL}$ of $0.1 \mathrm{M} \mathrm{NaCl}$. $\mathrm{CrO}_{4}^{-2}$ concentration in the solution was determined by Raman spectroscopy using a calibration curve based on the $848 \mathrm{~cm}^{-}$ ${ }^{1}$ Raman band. Aging times refer to drying time (in air) of the CCC film before application of the $1.0 \mathrm{~mL}$ of $\mathrm{NaCl}$ solution.

Protection of the initially untreated sample by migrating chromate in the artificial scratch cell implies that low concentrations of chromate can protect the alloy without other Alodine components present. To test this possibility, a polished but unprotected alloy sample was placed in a solution containing $\mathrm{K}_{2} \mathrm{CrO}$, and $0.1 \mathrm{M} \mathrm{NaCl}$. The $\mathrm{CrO}_{4}^{-2}$ concentration was $8 \times 10^{-5} \mathrm{M}$, approximately the level released from the CCC film into a water droplet, as shown in Fig. 8. The $\mathrm{pH}$ was adjusted to 5.2 with $\mathrm{HC} 1$, approximately the value observed in the artificial scratch experiments, and the solution was exposed to air. The polarization resistance for the unprotected alloy placed in this solution increased from $<10^{4} \Omega \mathrm{cm}^{2}$ to between 0.3 and $3.0 \times 10^{6} \mathrm{ft} \mathrm{cm}^{2}$ within the first hour. The course of $E_{\text {corr }}$ and $E_{\text {brk }}$ for the alloy as a function of time in the chloride and dilute $\mathrm{CrO}_{4}^{-2}$ solution are shown in Fig. 9. After 5 days, the difference between $E_{\text {brk }}$ and $E_{\text {corr }}$ was $>300 \mathrm{mV}$. For the entire observation period, the sample remained shiny, with no visually observable corrosion. Microscopic examination revealed small light and dark pits, similar to those observed in the migration experiments. Nineteen Raman spectra were acquired while the sample was translated by $540 \mu \mathrm{m}$, such that the spectrometer sampled the alloy surface both on the unpitted surface and on a light pit, with a spatial resolution of about $25 \mu \mathrm{m}$. The results are shown in Fig. 10, with the pit located in the range of $350-450 \mu \mathrm{m}$ on the distance axis. The chromate Raman band was below the detection limit on the unpitted region, but quite clear inside the light pit. As noted earlier, $\mathrm{Cr}$ (III) or Cr(VI) species may be present on the smooth regions, but at levels too low to observe.

Potentiodynamic polarization curves are shown in Fig. 11. In air-exposed $0.1 \mathrm{M} \mathrm{NaCl}$, the corrosion potential of 2024-T3 is determined by the pitting potential because of the relative nonpolarizability of the anodic pit growth reaction. A freshly polished 2024-T3 sample (solid line) exhibits a pitting potential in air-exposed $0.1 \mathrm{M} \mathrm{NaCl}$ of about $-550 \mathrm{mV} \mathrm{SCE}$, which is more noble than that for pure Al. The dashed line in Fig. 11 shows the behavior of a 2024-T3 sample that was polished, then immersed for $45 \mathrm{~h}$ in an air-exposed solution of $0.10 \mathrm{M} \mathrm{NaCl}$ containing $8.0 \times 10^{-5} \mathrm{M} \mathrm{K}_{2} \mathrm{CrO}_{4}$. After rinsing the sample with water, polarization experiments were conducted in air-exposed $0.1 \mathrm{M} \mathrm{NaCl}$. The exposure solution thus mimics the environment near a scratch. The major difference in the polarization curve from that of freshly polished alloy is that the cathodic kinetics are reduced by over two orders of magnitude, which results in a 
lowering of the corrosion potential. In this case $E_{\text {corr }}$ is not set by the pitting potential, which is only slightly higher than that of a freshly polished sample.

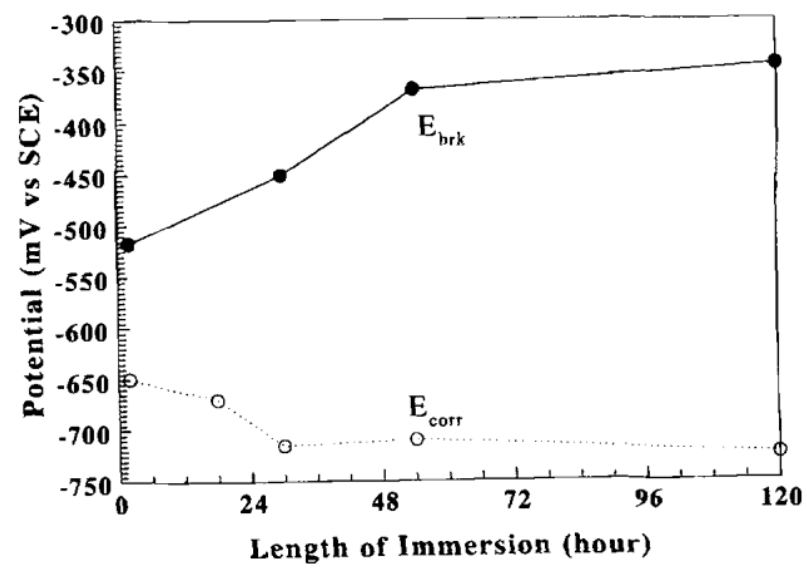

Fig. 9. Open-circuit potential $\left(E_{\text {corr }}\right)$ and breakdown potential $\left(E_{\text {brk }}\right)$ for an initially untreated alloy sample immersed in $0.1 \mathrm{M} \mathrm{NaCl}$ containing $8 \times 10^{-5} \mathrm{M} \mathrm{K}_{2} \mathrm{CrO}_{4} . E_{\text {corr }}$ and $E_{\text {brk }}$ were determined in the same solution, and a separate alloy sample was used to determine each pair of $\mathrm{E}_{\mathrm{corr}}$ and $E_{\mathrm{brk}}$ values.

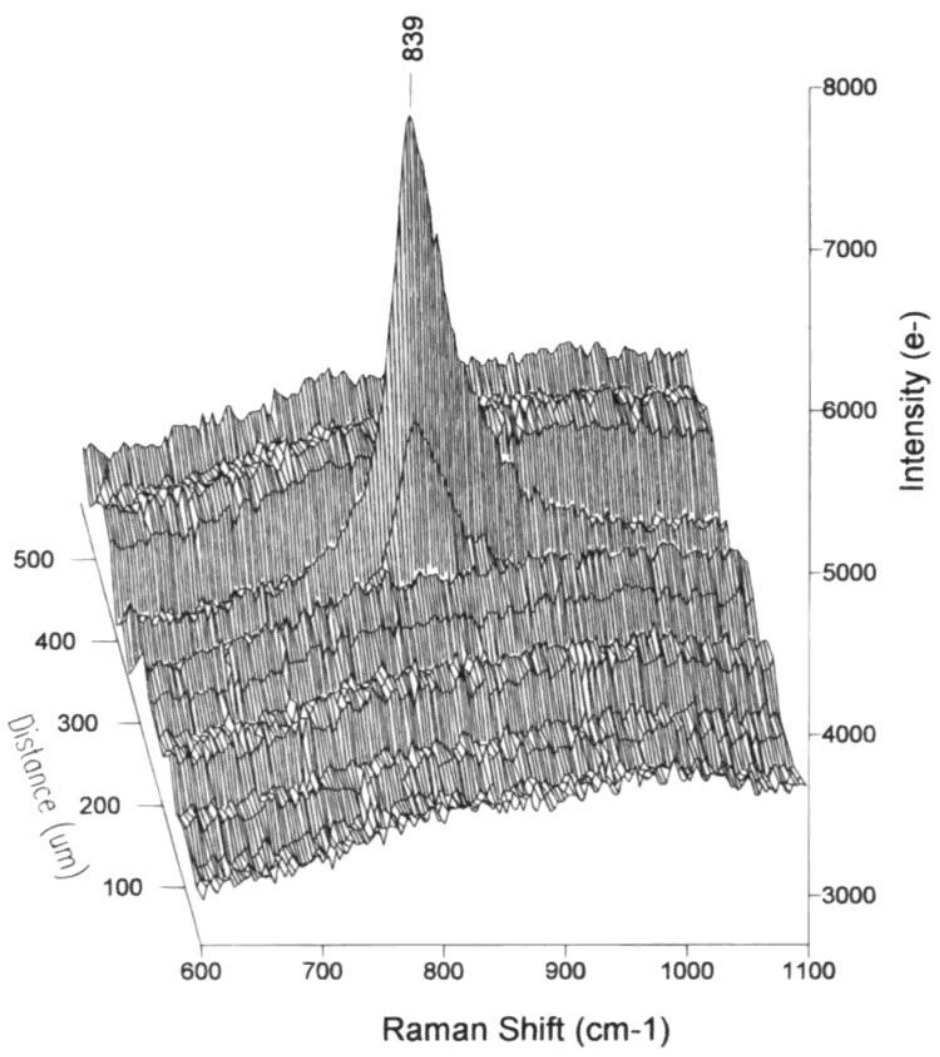

Fig. 10. Raman spectra of the alloy sample used to construct Fig. 9, after 5 days of immersion in $0.10 \mathrm{M} \mathrm{NaCl}$ containing $8 \times 10^{-5} \mathrm{M} \mathrm{K}_{2} \mathrm{CrO}_{4}$. The sample was translated laterally so that the laser focused crossed a light pit of about $50 \mu \mathrm{m}$ diam. The pit was visually observable between approximately 375 and $425 \mu \mathrm{m}$ on the distance scale. 


\section{Discussion}

Overall, the results clearly demonstrate that chromate is released from the CCC into the salt solution and can migrate to and protect a neighboring region of exposed or untreated alloy. The migrating species in the current experiments is $\mathrm{CrO}_{4}^{-2}$, but the $\mathrm{CrO}_{7}^{-2} / \mathrm{CrO}_{4}^{-2}$ equilibrium is $\mathrm{pH}$ and concentration dependent. Whether the untreated alloy was exposed to chromate released from a CCC or to a dilute $\mathrm{CrO}_{4}^{-2}$ solution, the chromate was concentrated in or near small, inactive pits, and produced a product with a Raman spectrum similar to the original Alodine CCC. The effect of dilute chromate on the initially unprotected alloy was to decrease $E_{\text {corr }}$ and increase $E_{\mathrm{brk}}$ and $R_{\mathrm{p}}$, thus decreasing the likelihood of pitting even upon subsequent exposure to a chromate-free chloride solution. At least under the conditions employed here, submillimolar $\mathrm{CrO}_{4}^{-2}$ is sufficient to protect the alloy in $0.1 \mathrm{M} \mathrm{NaCl}$. Other workers report that significantly higher $\mathrm{CrO}_{7}^{-2} / \mathrm{Cl}^{-}$ratios are required for protection. ${ }^{2,4}$

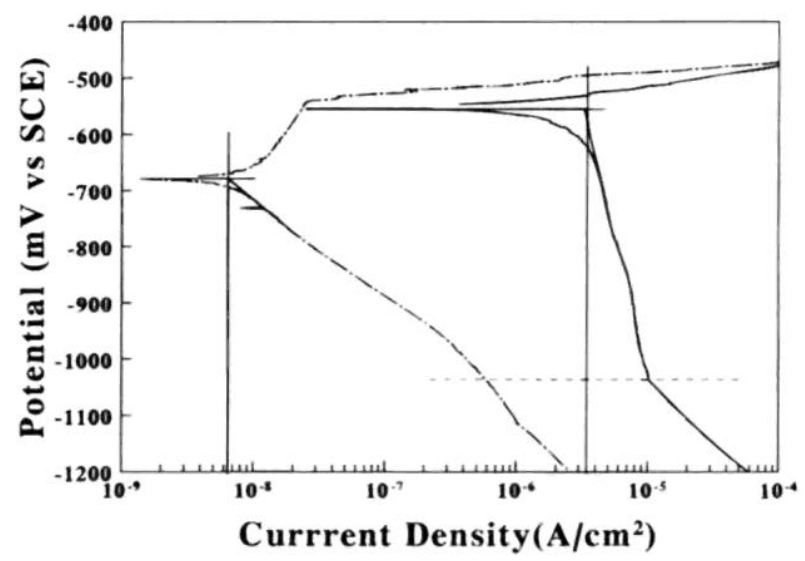

Fig. 11. Polarization curves of alloy samples in $0.1 \mathrm{M} \mathrm{NaCl}$. The solid line is untreated alloy after immersion in 0.1 $\mathrm{M} \mathrm{NaCl}$ for $2 \mathrm{~h}$. The dashed line is untreated alloy after $45 \mathrm{~h}$ of immersion in $0.1 \mathrm{M} \mathrm{NaCl} \mathrm{containing} 8 \times 10^{-5} \mathrm{M}$ $\mathrm{K}_{2} \mathrm{CrO}_{4}$.

The enrichment of $\mathrm{Cr}(\mathrm{VI})$ species in pits that occurs during migration is likely to be very important to corrosion protection. The mobility of $\mathrm{Cr}(\mathrm{VI})$ species in aqueous solution permits them to "seek out" pits and stop their growth. When diffusing chromate reaches a pit, it may adsorb to the previously formed corrosion product, or it may form a precipitate with $\mathrm{Al}^{+3}$. In either case, the insoluble $\mathrm{Cr}(\mathrm{VI})$ containing product deposits in or near a previously active corrosion site. The deposition of chromate species appears to be quite selective for corrosion sites, exactly where needed.

The chromate film on the initially untreated sample following migration is much thinner than a conventional CCC and may be localized to pits. Since the insoluble Cr(VI) product formed by corrosion enriches chromate at the active sites, a thick film may not be necessary. When forming a CCC, however, the intention is to cover the entire surface with a relatively thick film. The fluoride and ferricyanide in Alodine solutions are there to destabilize the Al(III) oxide, so the chromate may react with bare aluminum. Presumably the $\mathrm{Al}$ (III) or $\mathrm{Cr}$ (III) formed upon reduction of chromate reacts with or adsorbs additional chromate to form a yellow product responsible for the film color. The spectroscopic similarity of the CCC and the solid in the light pits implies that the solids have similar chemical composition and possibly similar formation 
mechanisms.

Important information can be learned about the influence of chromates on the corrosion of Al alloys by studying the potentiodynamic polarization curves shown in Fig. 11. The prolonged exposure of a polished sample to a chloride solution containing dilute chromate results in a reduction of the cathodic kinetics. So, whereas chromate is an oxidizing agent owing to the high reversible potential of the $\mathrm{Cr}(\mathrm{VI}) / \mathrm{Cr}$ (III) reactions, the result of this exposure was to inhibit the cathodic reaction. The reduction of chromate to a $\mathrm{Cr}$ (III) oxide apparently passivates the cathodic intermetallic particles by reducing their activity. Interestingly, the anodic aspects of pitting, the pitting potential, and nominal current density during pit growth, are not greatly influenced by this treatment.

The mechanism of inhibition by a chromate conversion can now be summarized. The coating provides a reservoir of chromate which can leach into an aqueous solution. While the amount of chromate that leaches out of a conversion coating is quite small, it is sufficient to have a considerable effect. Chromate or its reduction product is an effective cathodic passivator that inhibits the rate of cathodic reaction. Chromate itself accumulates at susceptible sites where small pits form, creating another local reservoir in case of further reaction. The composition and chemical behavior of the insoluble chromate containing precipitate are currently under investigation.

\section{Acknowledgment}

This work was supported by the Air Force Office of Scientific Research, contract no. F49620-96-1-0479.

The Ohio State University assisted in meeting the publication costs of this article.

\section{References}

1. Report by the Air Force Blue Ribbon Advisory Panel on Aircraft Coatings (Nov 1995).

2. H. Bohni and H. H. Uhlig, J. Electrochem. Soc., 116, 906 (1969).

3. S. T Pride, J. R. Scully, and J. L. Hudson, J. Electrochem. Soc., 141, 3028 (1994).

4. F Hunkeler and H. Bohni, Corrosion, 37, 645 (1981).

5. J. K. Hawkins, H. S. Isaacs, S. M. Heald, J. Tanquada, G. E. Thompson, and G. C. Wood, Corros. Set., 27, 391(1987).

6. S. W. M. Chung, J. Robinson. G. E. Thompson, G. C. Wood, and H. S. Isaacs, Philos. Mag. B, 63, 557 (1991).

7. J. S. Wainwright, O. J. Murphy, and M. R. Antonio, Corros. Sci., 33, 281 (1992).

8. C. Edeleanu and U. R. Evans, Trans. Faraday Soc., 47, 1121 (1951).

9. M. W. Kendig, A. J. Davenport, and H. S. Isaacs, Corros. Sci., 34, 41 (1993).

10. H. A. Katzman, G. M. Malouf, R. Bauer, and G. W. Stupian, Appl. Surf. Sci., 2, 416 (1979).

11. M. A. Heine and M. J. Pryor, J. Electrochem. Soc., 114, 1001(1967).

12. F W Lytle, R. B. Greegor, G. L. Bibbins, K. Y. Biohowiak, R. E. Smith, and G. D. Tuss, Corros. Sci., 37, 349 (1995).

13. Vibrational Spectroscopy of Molecules at Surfaces, J. T. Yates and T E. Madey, Editors, Plenum, New York (1987).

14. R. Caudano, J.-M. Gilles, and A. A. Lucas, Vibrations at Surfaces, Plenum, New York (1982).

15. R. J. Gale, Spectroelectrochemistry, Plenum, New York (1982).

16. A. Campion, J. K. Brown, and V. M. Grizzle, Surf. Sci. Lett., 115, L153 (1982).

17. S-L. Yau. X. Gao, S-C. Chang, B. Schardt, and M. Weaver, J. Am. Chem. Soc., 113, 6049 (1991).

18. R. L. McCreery, Prog. Anal. Spectrosc., 11, 141 (1988).

19. R. L. McCreery and R. T Packard, Anal. Chem., 61, 775A(1989).

20. C. A. Melendres, N. Pankucyh, Y. S. Li, and R. Knight, Electrochim. Acta, 37, 2747 (1992).

21. M. Thieme et al., J. Nucl. Mater., 189, 303 (1992).

22. D. J. Gardiner, M. Bowden, and P. R. Graves, Philos.Trans. R. Soc. London, Ser. A, 320, 295 (1986). 
23. C. Johnson, Vib. Spectosc., 1, 87 (1990).

24. A. Ahern, Proc. SPIE-lnt. Soc. Opt. Eng., 72, 1637 (1992).

25. Y-C. Liu and R. L. McCreery, J. Am. Chem. Soc., 117, 11254 (1995).

26. M. R. Kagan and R. L. McCreery, Langmuir, 11, 4041 (1995).

27. Y-C Liu and R. L. McCreery, Anal. Chem., 69, 2091(1997).

28. M. Kendig, M. Cunningham, S. Jeanjaquet, and D. Hardwick, J. Electrochem. Soc., 144, 3721 (1997).

29. G. Halada and C. Clayton, J. Electrochem. Soc., 138, 2921 (1991).

30. S Suzuki, I. Masaki, and Y. Waseda, Surf. Interface Anal., 25, 161 (1997).

31. A. E. Hughes, R. J. Taylor, and B. R. W. Hinton, Surf Interface Anal., 25, 223 (1997). 